\title{
Tracing ancestor rice of Suriname Maroons back to its African origin
}

\author{
Tinde R. van Andel ${ }^{1,2 \star}$, Rachel S. Meyer ${ }^{3 \star}$, Saulo A. Aflitos ${ }^{1}$, Judith A. Carney ${ }^{4}$, Margaretha \\ A. Veltman', Dario Copetti ${ }^{5}$, Jonathan M. Flowers ${ }^{3,6}$, Reinout M. Havinga7, Harro Maat ${ }^{8}$, \\ Michael D. Purugganan ${ }^{3,6}$, Rod A. Wing ${ }^{5,9}$ and M. Eric Schranz ${ }^{1}$
}

\begin{abstract}
African rice (Oryza glaberrima) and African cultivation practices are said to have influenced emerging colonial plantation economies in the Americas ${ }^{1,2}$. However, the level of impact of African rice practices is difficult to establish because of limited written or botanical records ${ }^{2,3}$. Recent findings of 0. glaberrima in rice fields of Suriname Maroons bear evidence of the high level of knowledge about rice among African slaves and their descendants, who consecrate it in ancestor rituals $^{4,5}$. Here we establish the strong similarity, and hence likely origin, of the first extant New World landrace of O. glaberrima to landraces from the Upper Guinean forests in West Africa. We collected African rice from a Maroon market in Paramaribo, Suriname, propagated it, sequenced its genome ${ }^{6}$ and compared it with genomes of 109 accessions representing 0 . glaberrima diversity across West Africa. By analysing 1,649,769 single nucleotide polymorphisms (SNPs) in clustering analyses, the Suriname sample appears sister to an Ivory Coast landrace, and shows no evidence of introgression from Asian rice. Whereas the Dutch took most slaves from Ghana, Benin and Central Africa ${ }^{7}$, the diaries of slave ship captains record the purchase of food for provisions when sailing along the West African Coast $^{8}$, offering one possible explanation for the patterns of genetic similarity. This study demonstrates the utility of genomics in understanding the largely unwritten histories of crop cultures of diaspora communities.
\end{abstract}

The forced migration of Africans to the Americas continued for 350 years and included over 35,000 transatlantic voyages with about 12.5 million enslaved Africans ${ }^{7}$. The transatlantic slave trade resulted in many introductions of African plants to the New World. Crops without immediate commercial value for the colonizers were cultivated by enslaved Africans in their dooryard gardens and forest fields, using leftover seeds from slave ship holds ${ }^{9,10}$. Most research on plantation slavery focuses on the production of export crops, and less attention has been paid to the food regimes on which this enveloping economic system subsisted. Slave traders sailing along the western African coast purchased substantial quantities of locally produced food to feed their human cargoes ${ }^{1}$. One of these staples was rice. In Africa, a distinct species is grown, known as African rice (Oryza glaberrima Steud.), domesticated in western sub-Saharan Africa 3,500 years ago ${ }^{11}$ independently from Asian rice (O. sativa L.), which was domesticated in China $\sim 9,000$ years ago $^{12}$. The introduction of Asian rice to Africa pre-dates the period of slavery ${ }^{13}$ and both species are grown by African farmers ${ }^{14}$. Under wet conditions, African rice generally gives lower yields than Asian rice, but it is better adapted to low-input agriculture, drought, poor and acid soils, pests and weeds ${ }^{15}$.

The discovery in 2008 of African rice in a Maroon field in Suriname $^{7}$ testifies to the agency of enslaved Africans in the transatlantic distribution of crops and the conservation of cultivation practices by Maroons, descendants of escaped plantation slaves who settled in remote rainforests of Suriname and French Guiana between 1670 and 1860 . Here we present the genetic evidence that the Surinamese 'black rice' is O. glaberrima and infer its likely origin. This evidence is an incentive to re-examine historical sources to trace the way African rice ended up in the New World and why it was cultivated by enslaved Africans and their descendants.

The records of slave ship captains reveal that rice was frequently bought in West Africa to feed their captives ${ }^{2}$. An example is the recently digitized logbook of the Dutch slave ship D'Eenigheid (the Unity), sailing in 1761 from Vlissingen, the Netherlands, which reports purchases of rice in West Africa ${ }^{8}$. Before leaving from Elmina in Ghana with 319 enslaved Africans destined for Dutch plantations in Guyana, the crew of D'Eenigheid bought slaves and provisions along the coast of Liberia and Ivory Coast. Besides millet and sorghum, rice was purchased in 'makoeten' (baskets) and 'coffers' (chests of approximately $625 \mathrm{~kg}$ ) from African merchants approaching the ships by canoe ${ }^{8}$ (Fig. 1).

Leftover rice stock from slave ships was sometimes distributed among plantations ${ }^{16}$ or smuggled away by slaves and planted in

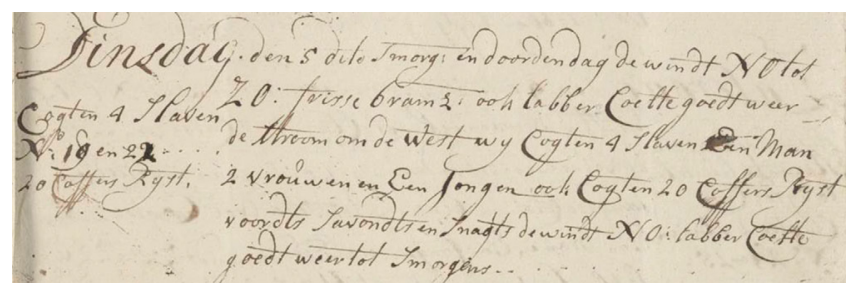

Figure 1 | Logbook entry of the Dutch slave ship D'Eenigheid. On 5 January 1762 , the crew bought four slaves (' 4 slaven') and 20 chests of rice ('20 coffers rijst') near Kwa Kola on the coast of Liberia ${ }^{8}$. Figure reproduced from ref. 8, Zeeland Archives.

'Biosystematics group, Wageningen University, PO Box 16, 6700 AP, Wageningen, The Netherlands. ${ }^{2}$ Naturalis Biodiversity Center, PO Box 9517,2300 RA, Leiden, The Netherlands. ${ }^{3}$ Department of Biology, Center for Genomics and Systems Biology, New York University, 12 Waverly Place, New York, New York 10003, USA. ${ }^{4}$ Departmemt of Geography, University of California, Box 951524, Los Angeles, California 90095, USA. ${ }^{5}$ Arizona Genomics Institute, School of Plant Sciences, University of Arizona, 1657 E. Helen Street, Tucson, Arizona 85721, USA. ${ }^{6}$ Center for Genomics and Systems Biology, New York University Abu Dhabi, Saadiyat Island, PO Box 129188, Abu Dhabi, United Arab Emirates. ${ }^{7}$ Hortus Botanicus Amsterdam, Plantage Middenlaan 2, 1018 DD, Amsterdam, The Netherlands. ${ }^{8}$ Knowledge Technology and Innovation group, Social Sciences Department, Wageningen University, PO Box 8130,6700 EW, Wageningen, The Netherlands. ${ }^{9}$ International Rice Research Institute, Genetic Resource Center, Los Baños, Laguna, Philippines.

*e-mail: tinde.vanandel@naturalis.nl; rsmeyer@ucla.edu 


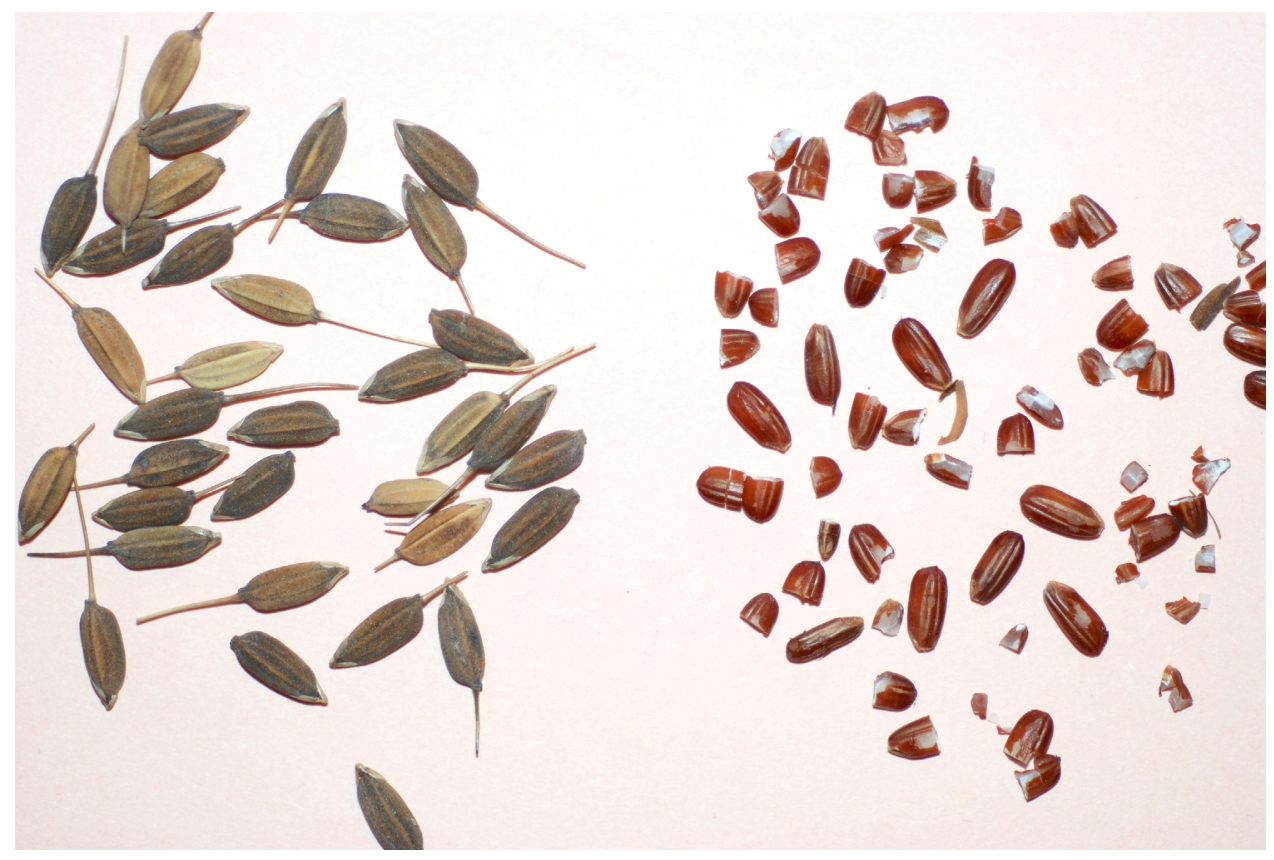

Figure 2 | The Surinamese Oryza glaberrima sample (TVA5634) that was propagated to sequence its genome. Seeds still in the husk (left) and dehusked (right). Picture courtesy of C.A. van der Hoeven.

their provision gardens ${ }^{9}$. More than merely a labour force, African knowledge of upland and lowland rice cultivation, harvesting and milling was a key resource for rice cultivation in the Americas, especially in the South Carolina wetlands ${ }^{1,2}$. O. glaberrima, which needs to be dehusked by hand with a wooden pestle in a mortar, was probably the first rice planted in the New World ${ }^{2}$. Evidence for the presence of African rice in the early days of plantation history, however, is only provided by a few written records from the eighteenth century on the red husks of the crop ${ }^{2,4}$ and a single O. glaberrima sample collected in 1938 from a Maroon field in French Guiana ${ }^{3,17}$. In 1955, this sample was considered to be morphologically identical to three O. glaberrima landraces grown by Mande-speaking people from the eastern Guinea highlands ${ }^{3}$.

There is no evidence of commercial, slave-based rice plantations in the Guianas, but in 1718, rice was observed in gardens of enslaved people in Suriname ${ }^{18}$. The importance of rice as a staple food for escaped slaves became evident as military expeditions stumbled on extensive rice fields in the refugees' forest camps ${ }^{19}$. Maroons have practised slash-and-burn agriculture for centuries in relative isolation from the coastal plantations and maintained much of their traditional language, culture, music and religion ${ }^{20}$. After slavery was abolished in 1863, Creoles largely abandoned agriculture. Crop cultivars once commonly grown by people of African descent on plantations are now only encountered in Maroon fields ${ }^{5}$.

Rice is the staple food of the Maroons and forms an integral part of their culture ${ }^{20}$. Dozens of different landraces of upland, rain-fed $O$. sativa have been reported from their fields, including a type of 'black' or 'forest rice' mainly used in rituals $\mathrm{s}^{17,20-22}$. Voucher collection, however, has been minimal until 2006, when a small bag of unmilled 'black rice' grains with dark brown husks, long, straight awns and red bran was collected in a Maroon market in Paramaribo ${ }^{4}$ (Fig. 2). This appeared to be the first known O. glaberrima collection in the New World after the French Guiana voucher from 1938.

Flowering and fruiting individuals of African rice and additional seeds were collected afterwards in several Maroon villages ${ }^{4,5}$. Maroons distinguish just one landrace of O. glaberrima, which they occasionally consume, but mostly use unprocessed in herbal baths and food offerings to the ancestors. Unmilled seeds are also sprinkled on newly cut fields before burning to ensure a better harvest ${ }^{4,5}$. During funerals, bowls of cooked rice from diverse landraces are placed near the graves of the deceased ${ }^{20}$.

Small-scale farmers across West Africa grow a wide variety of $O$. glaberrima and $O$. sativa landraces, and hybrids between the two species that are either selected by farmers or developed artificially to combine the high yield of Asian rice with the hardiness of African rice ${ }^{14}$. Unlike the Maroon rice, African landraces of both species are well represented in germplasm institutes. Recently, the genome sequence of $O$. glaberrima was published ${ }^{23}$ and whole genome resequencing SNP maps of 20 diverse samples ${ }^{23}$ and 93 West African landraces ${ }^{11}$ were completed, providing a novel and challenging opportunity to match Suriname rice to its African closest relatives.

The aim of this study was to trace the African ancestry of the Surinamese O. glaberrima sample, by assessing its genetic similarity to 109 accessions of the same species across West Africa (Supplementary Table 1), and to ascertain whether this origin coincides with the regions where the Dutch purchased slaves and rice. We also evaluate the degree of genomic divergence of New World African rice that has been grown under traditional Maroon cultivation, likely to have been in close proximity to Asian landraces, for several hundred years.

A single Surinamese sample germinated successfully in the Netherlands. One $\mathrm{F}_{5}$ was resequenced to $8.3 \times$ coverage and aligned to the O. glaberrima reference genome AGI 1.1 (ref. 23). We created a set of 1,649,769 SNPs (Supplementary Table 3) and used them in genomic, population genetic and clustering analyses. The Surinamese sample, having been maintained in a limited population size and having been sequenced at the $\mathrm{F}_{5}$ generation, was surprisingly close to the average heterozygosity at $5.4 \%$, on par with levels in Africa (Supplementary Table 2). For reference, O. sativa heterozygosity has been reported to be as high as $15 \%$ (breeding centres) $^{24}$ and as low as $2 \%$ (Pakistan rice) ${ }^{25}$.

Although Maroons sometimes sow African rice on separate fields, the crop often grows in close proximity to Asian landraces. However, there was no apparent introgression between the Surinamese O. glaberrima sample and Asian rice.

In an EIGENSTRAT principal component analysis of genomic variation (Fig. 3a and Supplementary Fig. 1), the Surinamese 

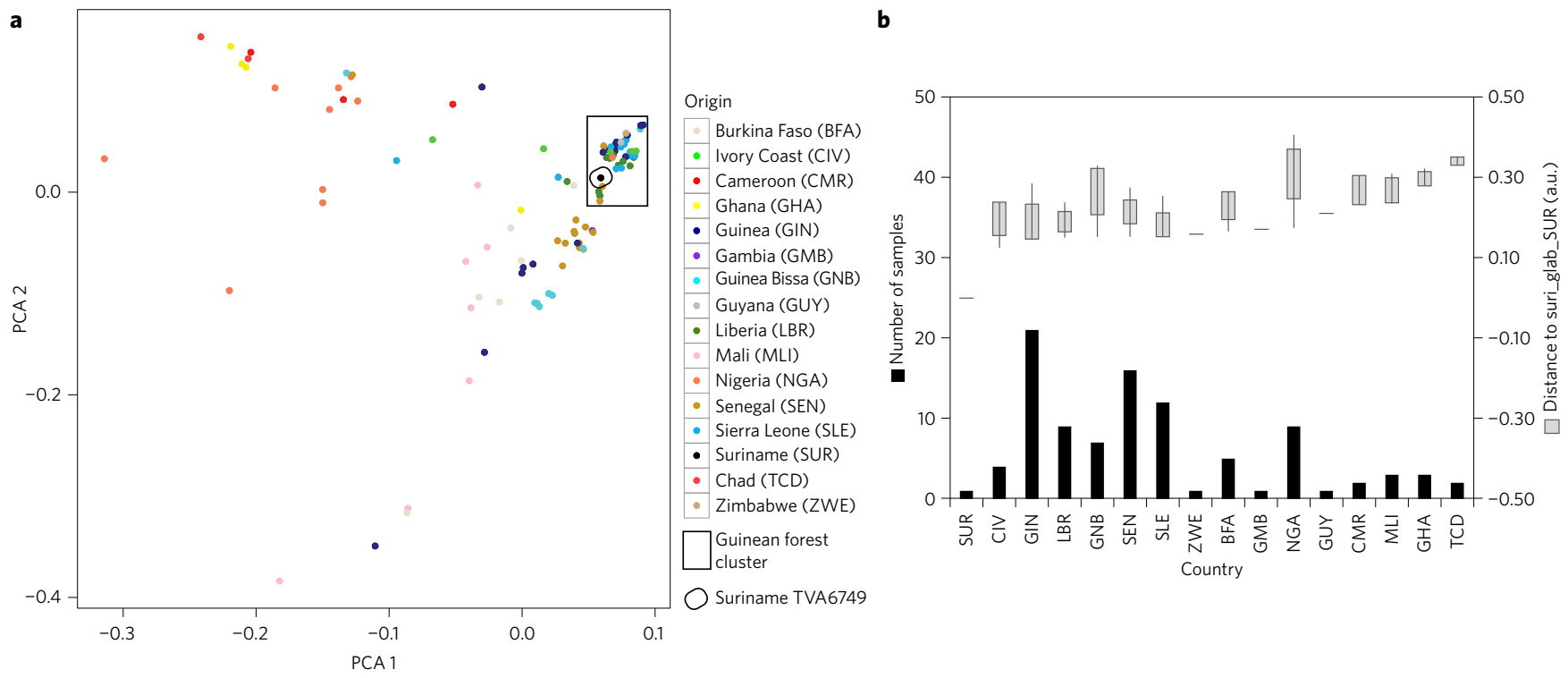

Figure 3 | Comparison of the Surinamese sample with 109 accessions representing 0 . glaberrima diversity across West Africa. a, Principal component analysis (PCA) of the 110 O. glaberrima accessions, including the Surinamese sample: two-dimensional plots of the first two principal components. b. Accessions grouped according to country. Black bars, the number of samples; grey box and whisker, the minimum, maximum, \pm population s.d. of the clustering distance to the Suriname accession (suri_glab_SUR). Kruskal-Wallis multiple comparison tests (Supplementary Information Table 6) indicated that Nigeria was significantly more distant than Sierra Leone and Guinea.

a

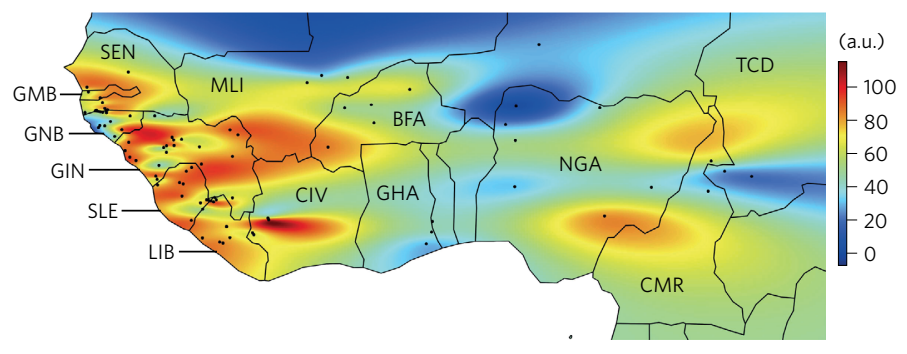

b

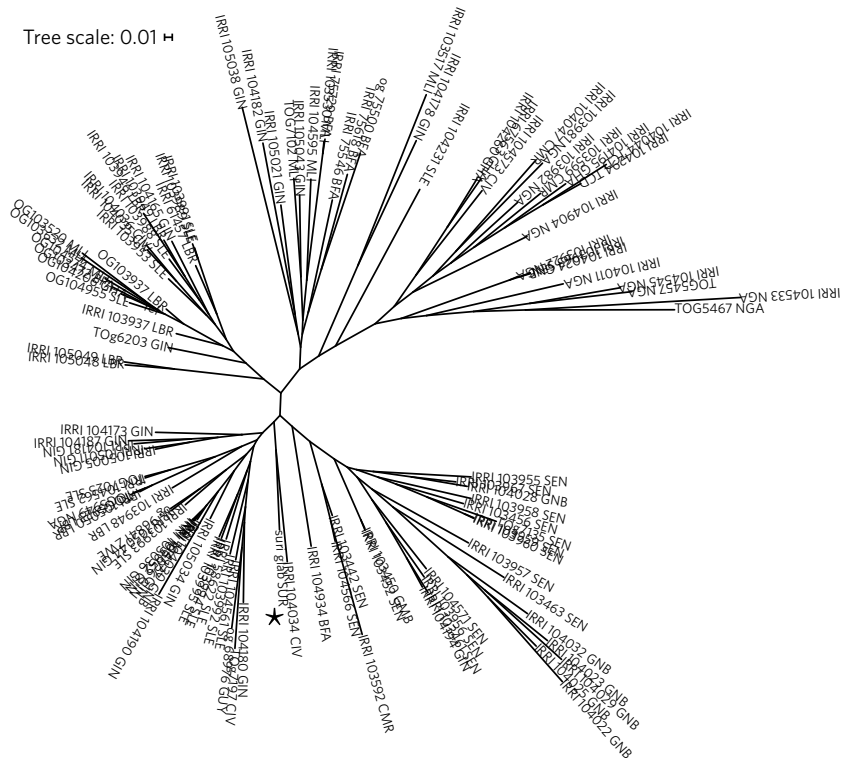

Figure 4 | Heat map of clustering similarity distances to the Surinamese sample, and clustering tree. a, Thin plate spline (TPS) heat map showing the clustering distances from 93 West African O. glaberrima samples to the Surinamese sample, interpolated across the West African map. Minimum distance ( 0.1248 , converted to 100 , red) and maximum distance $(0.40603$, converted to 0 , blue). b. Maximum likelihood (ML) tree showing that the Surinamese sample (suri_glab_SUR, indicated with a star) is sister to IRRI 104034 from the Ivory Coast.

sample clusters near a group largely consisting of Western Guinean forest countries. Genetic distance was calculated using concatenated SNPs following a modified ${ }^{26}$ methodology, where distances to the Surinamese sample showed that the Western Guinean forest countries were closer than Eastern countries (Fig. $3 \mathrm{~b}$ and Supplementary Fig. 2). With the only two records of African rice landraces in the New World resembling Guinean forest zone types, it is either the only type brought across the Atlantic, or the only type adequately pre-adapted to the Neotropical rainforest. More specifically, results show the closest kinship between the Surinamese accession and a landrace from the western Ivory
Coast (IRRI 104034), collected in Blolé, a village $\sim 20 \mathrm{~km}$ south of the city of Man, and $\sim 300 \mathrm{~km}$ from the coast (Fig. 4).

Even though the Surinamese accession is sister to an accession from Ivory Coast, it does not mean that the O. glaberrima landrace originated there. More likely, the ancestor of the Surinamese sample came with the people who now inhabit this particular region. Accession IRRI 104034 was collected in 1980 in a Dan-speaking area. Dan is part of the Mande language family, spoken in the northwestern Ivory Coast, Senegal, Guinea, Sierra Leone and Liberia, but unrelated to the Volta-Congo languages spoken in the greater part $(\sim 75 \%)$ of Ivory Coast ${ }^{27}$ (Supplementary Table 5 ). Mande speakers 
along the Niger River are thought to have participated in domesticating African rice. In the early sixteenth century, they moved southwards to the West African coast, bringing their rice culture with them. The Senegambian coast and the Guinean highlands then became secondary centres of diversification for O. glaberrima, during which adaptation to different microenvironments have occurred for millenia ${ }^{11,28,29}$. Observing the genetic distances calculated across the whole genome (Fig. 4a,b), the Surinamese sample is more similar to the coastal Guinean lowlands and central highlands than to the eastern Guinean highlands, to which the O. glaberrima from French Guiana has been previously linked ${ }^{3}$.

Rice-growing peoples historically inhabit both the Guinea lowlands and highlands: the Atlantic language groups cultivate rice in the brackish coastal swamps, and the Mande-speaking groups grow rain-fed varieties on higher ground ${ }^{27}$. The six rice accessions most similar to the Surinamese sample were collected from areas dominated by Mande farmers (Supplementary Table 5). Slaveholders in South Carolina preferred Mande-speaking peoples from the 'Rice Coast' (Guinea, Sierra Leone, Liberia and Ivory Coast) because of their rice cultivation skills ${ }^{27}$. To Dutch slave traders, however, this area was a minor supplier, from which approximately 80,000 people were sent to Suriname. The majority of enslaved Africans in the colony came from Ghana, Benin and Central Africa ${ }^{10}$. Nevertheless, Mande-speaking peoples made outsized contributions to Suriname's botanical history. Their knowledge of upland rice cultivation survives in the fields Maroons plant to this day, and words derived from Mande languages frequently appear in Maroon vernacular names for wild plants ${ }^{30}$.

Slave ship captains may have had little interest in Africa-grown provisions beyond the need to feed their prisoners, but the current ritual importance of African rice in Suriname underscores the deeper significance these staples held for the exiled captives. Maroon agriculture is threatened by large-scale gold mining, migration to the capital and the import of cheap rice. Such developments could lead to the abandonment of labour-intensive crops like rice, and the loss of traditional culture and religion may cause the disappearance of landraces grown for ritual purposes ${ }^{5}$. Modern genomics research on the unique landraces cultivated exclusively by these isolated diaspora communities can reveal the unwritten history of crop movement during one of the largest migrations in human history and offer new insights into African contributions to Atlantic history.

\section{Methods}

Between 2006 and 2013, fertile specimens of O. glaberrima and seeds kept for sowing material were collected near the Maroon villages Mundje Kreek $\left(5^{\circ} 10^{\prime} 21^{\prime \prime} \mathrm{N}-55^{\circ} 3^{\prime}\right.$ $\left.56^{\prime \prime} \mathrm{W}\right)$, Mooytaki ( $\left.4^{\circ} 7^{\prime} 38^{\prime \prime} \mathrm{N}-54^{\circ} 39^{\prime} 4^{\prime \prime} \mathrm{W}\right)$ and Jawjaw $\left(4^{\circ} 25^{\prime} 17^{\prime \prime} \mathrm{N}-55^{\circ} 22^{\prime}\right.$ $13^{\prime \prime}$ W, Supplementary Fig. 5$)^{4,5}$. Vouchers in Suriname were collected with permits issued by the Nature Conservation Division of the Suriname Forest Service and deposited at the National Herbarium of Suriname (BBS) and Naturalis Biodiversity Center (L). Rice farmers were interviewed after obtaining their prior informed consent. In 2009, three bags (approximately 60 grams each) of unmilled O. glaberrima grains were purchased from Maroon vendors at the Paramaribo Vreedzaam market, the main trading location for medicinal and ritual plants from the country's forested interior ${ }^{31}$. Grains from each sample were sown in 2010 in the greenhouse of the Hortus Botanicus Amsterdam. Only one sample (TVA5634) successfully grew into a fertile individual that produced viable seeds ${ }^{32}$. In 2014, we made a herbarium specimen with fully developed infructescences (TVA6749) of the fifth generation of this individual and extracted DNA from its fresh leaves, using the Qiagen DNeasy Plant Mini kits (Qiagen). A 300-600 bp genomic DNA paired-end library was constructed using Fragment Library System I with the automated system SPRT-TE (Beckman Coulter) system and sequenced as $2 \times 100 \mathrm{bp}$ on an Illumina HiSeq 2500.

Raw paired-end sequence reads from the Suriname sample were used in this study (Supplementary Table 1). This process was repeated for the 93 O. glaberrima accessions from Meyer et al. ${ }^{11}$ and for 16 of the accessions from Wang et al. ${ }^{23}$, obtained from the International Rice Research Institute (IRRI), the United States Department of Agriculture (USDA) and the AfricaRice Genetic Resource Center (GRC). All samples were landraces collected on farms, except og 68976 GUY and og 96841 ZWE (West African landraces grown in rice breeding stations in Guyana and
Zimbabwe). The Suriname reads were trimmed with Sickle ${ }^{33}$ (v1.33), aligned to the O. glaberrima reference sequence ${ }^{23}$, comprising 12 pseudomolecules and 1,939 scaffolds, with Burrows-Wheeler Aligner ${ }^{34}$ (BWA; v0.6.1) aln and sampe programs, and indexed bam files were created with SAMtools ${ }^{35}$ (v1.2). Read mate information was updated with FixMateInformation (Picard tools, v1.111) and duplicate reads were marked using MarkDuplicates (Picard tools) and removed from further consideration. Sample alignments were merged using MergeSamFiles (Picard tools) and reads globally realigned around indels using the GATK RealignerTargetCreator/ IndelRealigner protocol. SNP calling was performed on the merged alignment using the GATK UnifiedGenotyper. The set of 1,778,594 SNPs was derived from two steps of filtering. First, reads mapping to more than one region of the genome were removed ( $25 \%$ of reads) and base qualities capped at the minimum mapping quality of the read. Then, reads that failed any of the following filters were excluded: mapping quality below 30; depth of coverage greater than 4,987 (about $3.5 \times$ higher than the mean depth); Phred-scaled $P$ value using Fisher's exact test greater than 399.75; RMS Mapping Quality greater than 61.18; variant confidence/quality by depth $<0.32$; and Phred-scaled quality score $>117,254$. Only biallelic variant SNPs from chromosomes were retained, which reduced the SNP set to $1,649,769$ SNPs (Supplementary Table 3). Coverage was calculated using the GATK $^{36}$ (v.3.1-1) DepthOfCoverage tool. Heterozygosity was calculated using VCFtools ${ }^{37}$ (v.0.1.12b) '-het'.

Population eigenvectors for principal component analysis (PCA) were obtained using the program EIGENSOFT to run EIGENSTRAT ${ }^{38}$. Input SNPs were pruned to $1,244,261$ SNPs by using settings in PLINK $^{39}$ (v1.07) '-indep 505 1.5'. Eleven PCs were significant to $P<0.05$ and each accounted for only a small percentage of the variance; variance percentage was included in the PC labels (Supplementary Information Table 4). Two-dimensional PCA plots were made with the top three PCs in R (Supplementary Fig. 1). Clustering distance used in the heat maps (Fig. 4a; Supplementary Fig. 4) and trees (Fig. 4b; Supplementary Fig. 3) was calculated using a modified ${ }^{26}$ approach with Introgression Browser (vdef67dd) and FastTree $2^{40}$ (v2.1.7). As $99.9 \%$ of the polymorphic positions in the genome are excluded by the regular method of deleting positions in which any accession presents either no sequencing coverage, MNPs, InDels or heterozygous SNPs, we decided to keep heterozygous SNPs and regions of no coverage. This increases the number of available polymorphic positions to 1.6 million SNPs. The final clustering distance reported is the pairwise distance calculated from the resulting tree created by FastTree $2^{40}$ as extracted by ETE2 ${ }^{41}$ (v2.2rev1056). To map clustering distances to geographical coordinates, we conducted a Thin Plate Spline (TPS) regression analysis on all West African accessions using the packages 'fields' ${ }^{\text {'2 }}$, 'raster' ${ }^{\text {'3 }}$ and 'rworldmap' ${ }^{44}$ in $\mathrm{R}^{45}$ (v.3.2.3). Samples with low coverage $(<5 \times)$ were excluded to enhance the quality of the image, leaving 93 accessions available for the analysis. Distances were interpolated across a geographical region from $0^{\circ}$ to $20^{\circ}$ latitude and $-20^{\circ}$ to $20^{\circ}$ longitude with smoothing parameter lambda set to 0.001 . To test whether a different clustering method would produce similar results, we calculated a second genetic distance estimate (Supplementary Fig. 3). This was a neighbourjoining tree from the 110 O. glaberrima samples using 494,939 biallelic SNPs, allowing for missing genotypes. Distances were calculated using the equation described earlier ${ }^{6,46}$ and reproduced here:

$$
d(X, Y)=\frac{1}{L} \sum_{i=1}^{L}\left(1-\frac{1}{2} \max \left(\delta_{a_{i} c_{i}}+\delta_{b_{i} d_{i}}, \delta_{a_{i} d_{i}}+\delta_{b_{i} c_{i}}\right)\right)
$$

Data availability. All O. glaberrima collections and associated information from Suriname are digitally available at the collections database of Naturalis Biodiversity Center (http://bioportal.naturalis.nl).

Received 22 March 2016; accepted 30 August 2016; published 3 October 2016

\section{References}

1. Wood, P. H. Black Majority: Negroes in Colonial South Carolina from 1670 through the Stono Rebellion (A.A. Knopf Inc., 1974).

2. Carney, J. A. Black Rice: The African Origins of Rice Cultivation in the Americas (Harvard Univ. Press, 2009).

3. Portères, R. Présence ancienne d'une variété cultivée d'Oryza glaberrima Steud. en Guyane Française. J. Agric. Trop. Bot. Appl. 2, 680 (1955).

4. Van Andel, T. R. African rice (Oryza glaberrima Steud.): lost crop of the enslaved Africans discovered in Suriname. Econ. Bot. 64, 1-10 (2010).

5. Van Andel, T. R., Van der Velden, A. \& Reijers, M. The 'Botanical Gardens of the Dispossessed' revisited: richness and significance of Old World crops grown by Suriname Maroons. Genet. Resour. Crop Evol. 63, 695-710 (2016).

6. Gronau, I., Hubisz, M. J., Gulko, B., Danko, C. G. \& Siepel, A. Bayesian inference of ancient human demography from individual genome sequences. Nat. Genet. 43, 1031-1034 (2011).

7. Eltis, D. \& Richardson, D. Atlas of the Transatlantic Slave Trade (Yale Univ. Press, 2010).

8. MCC Slave Voyage the Unity 1761-1763. http://eenigheid.slavenhandelmcc.nl/? lang=en (2013). 
9. Carney, J. A. \& Rosomoff, R. N. In the Shadow of Slavery: Africa's Botanical Legacy in the Atlantic World (Univ. California Press, 2009).

10. Voeks, R. A. \& Rashford, J. African Ethnobotany in the Americas (Springer, 2012).

11. Meyer, R. S. et al. Domestication history and geographic adaptation inferred from a SNP map of African rice. Nat. Genet. 48, 1083-1088 (2016)

12. Molina, J. et al. Molecular evidence for a single evolutionary origin of domesticated rice. Proc. Natl. Acad. Sci. 108, 8351-8356 (2011).

13. Gilbert, E. in Rice: Global Networks and New Histories (ed. Bray, F. et al.) 212-228 (Cambridge Univ. Press, 2015).

14. Nuijten, E., van Treuren, R., Struik, P. C., Mokuwa, A. \& Okry, F. Evidence for the emergence of new rice types of interspecific hybrid origin in West African farmers' fields. PLoS ONE 4, e7335 (2009).

15. Sakagami, J. I., Joho, Y. \& Sone, C. Complete submergence escape with shoot elongation ability by underwater photosynthesis in African rice, Oryza glaberrima Steud. F. Crop. Res. 152, 17-26 (2013).

16. Collinson, P. Of the introduction of rice and tar in our colonies. Gentleman's Magazine 278-280 (1766).

17. Vaillant, M. Milieu cultural et classification des variétés de riz des Guyanes française et hollandaise. Rev. Int. Bot. Appl. d'Agriculture Trop. 28, 520-529 (1948).

18. Herlein, J. D. Beschryvinge van de volk-plantinge Zuriname (Meindert Injema, 1718).

19. Stedman, J. G. Narrative of a Five Years' Expedition, against the Revolted Negroes of Surinam 1790 (Johns Hopkins Univ. Press, 1988).

20. Price, S. Co-Wives and Calabashes (Univ. Michigan Press, 1993).

21. Geijskes, D. C. De landbouw bij de Bosnegers van de Marowijne. West-Indische Gids. 35, 135-153 (1955).

22. Baumgart, I. R., HilleRisLambers, D., Khodabaks, M. R. \& Wildschut, J. Visit to rice growing sites on the Upper Suriname River between Nieuw Aurora and Abenaston, June 7-10 1998 (ADRON, 1998).

23. Wang, M. et al. The genome sequence of African rice (Oryza glaberrima) and evidence for independent domestication. Nat. Genet. 46, 982-988 (2014).

24. Mehra, P., Pandey, B. K. \& Giri, J. Genome-wide DNA polymorphisms in low Phosphate tolerant and sensitive rice genotypes. Sci. Rep. 5, 13090 (2015).

25. Shah, S. M., Arif, M., Aslam, K., Shabir, G. \& Thomson, M. J. Genetic diversity analysis of Pakistan rice (Oryza sativa) germplasm using multiplexed single nucleotide polymorphism markers. Genet. Resour. Crop. Evol. 63, 1113-1126 (2016).

26. Aflitos, S. A. et al. Introgression browser: high-throughput whole-genome SNP visualization. Plant J. 82, 174-182 (2015).

27. Fields-Black, E. L. Deep Roots: Rice Farmers in West Africa and the African Diaspora (Indiana Univ. Press, 2008).

28. Portères, R. in Origins of African Plant Domestication (ed. Harlan, J. R.) 409-452 (Mouton Publishers, 1976).

29. Harlan, J. R. Origins of African Plant Domestication (Mouton Publishers, 1976).

30. Van Andel, T. R. et al. Local plant names reveal that enslaved Africans recognized substantial parts of the New World flora. Proc. Natl Acad. Sci. USA 111, E5346-E5353 (2014).

31. van Andel, T. R., Behari-Ramdas, J. A., Havinga, R. M. \& Groenendijk, S The medicinal plant trade in Suriname. Ethnobot. Res. Appl. 5, 351-372 (2007).

32. Taxon: Oryza glaberrima. Accession number AMD 20101002 Hortus Botanicus Amsterdam, the Netherlands; http://dehortus.gardenexplorer.org/taxon-3625.aspx

33. Joshi, N. A. \& Fass, J. N. Sickle: a sliding-window, adaptive, quality-based trimming tool for FastQ files Version 1.33 (2011); https://github.com/najoshi/ sickle
34. Li, H. \& Durbin, R. Fast and accurate long-read alignment with Burrows-Wheeler transform. Bioinformatics 26, 589-595 (2010).

35. Li, H. et al. The Sequence Alignment/Map format and SAMtools. Bioinformatics 25, 2078-2079 (2009)

36. McKenna, A. et al. The Genome Analysis Toolkit: a MapReduce framework for analyzing next-generation DNA sequencing data. Genome Res. 20, 1297-1303 (2010).

37. Daneck, P. et al. The variant call format and VCFtools. Bioinformatics 27, 2156-2158 (2011).

38. Price, A. L. et al. Principal components analysis corrects for stratification in genome-wide association studies. Nat. Genet. 38, 904-909 (2006).

39. Purcell, S. et al. PLINK: A tool set for whole-genome association and population-based linkage analyses. Am. J. Hum. Genet. 81, 559-575 (2016).

40. Price, M. N., Dehal, P. S. \& Arkin, A. P. Fasttree 2 - approximately maximumlikelihood trees for large alignments. PLoS ONE 5, e9490 (2010).

41. Huerta-Cepas, J., Dopazo, J. \& Gabaldón, T. ETE: a python environment for tree exploration. BMC Bioinformatics 11, 24 (2010).

42. Nychka, D., Furrer, R., Paige, J. \& Sain, S. Fields: Tools for Spatial Data R package version 8.3-6 (2016)

43. Hijmans, R. J. Raster: Geographic Data Analysis and Modeling R package version 2.5-2 (2015); https://cran.r-project.org/package=raster

44. South, A. Rworldmap: a new R package for mapping global data. R. J. 3, 35-43 (2011).

45. R Core Team. R: A Language and Environment for Statistical Computing (R Foundation for Statistical Computing, 2012); http://www.r-project.org

46. Freedman, A. H. et al. Genome sequencing highlights the dynamic early history of dogs. PLoS Genet. 10, e1004016 (2014).

\section{Acknowledgements}

We would like to thank rice farmers in Jawjaw, Mundje Kreek, Mooytaki and Paramaribo for sharing their knowledge on African rice with us. T. Polimé and B. Poeketie facilitated fieldwork in Maroon communities. C.-R. Lee helped us with the TPS analysis. This research was funded by the Biosystematics group of Wageningen University, Naturalis Biodiversity Center (Leiden), as well as support from NSF Plant Genome to R.S.M. (IOS-1202803) and M.D.P. (IOS-1126971), a TKI-Horticulture Grant to M.E.S. and S.A.A., grants from the US National Science Foundation and the NYU Abu Dhabi Research Institute to J.M.F., and the AXA Chair in Genome Biology and Evolutionary Genomics to R.A.W.

\section{Author contributions}

T.R.v.A. conducted the fieldwork in Suriname, and wrote the paper with contributions and input from all co-authors. T.R.v.A. and M.E.S. conceived and guided the research. R.M.H. maintained the living collection of Oryza glaberrima from Suriname used in this project. D.C. performed sequencing and assisted with data analysis. R.S.M. and J.M.F. performed alignments, SNP calling, and clustering analyses. S.A.A. and M.A.V. performed phylogenomic and TPS analysis. J.A.C. and H.M. provided background on the geographica and historical aspects of West African rice, slavery and Suriname. R.A.W. and M.D.P. helped to collect the data.

\section{Additional information}

Supplementary information is available for this paper. Reprints and permissions information is available at www.nature.com/reprints. Correspondence and requests for materials should be addressed to T.R.v.A. and R.S.M.

\section{Competing interests}

The authors declare no competing financial interests. 